Bundesgesundheitsbl - Gesundheitsforsch Gesundheitsschutz 2003 - 46:508-513 DOI 10.1007/s00103-003-0615-4

Forschung aktuell

E. Hildt · E. Bleifuß - B. Brandenburg - T. Bürckstümer · R. Foerste · A. Hillemann · H. Huser · M. Kriegs · F. Löffelbein · B. Malkowski $\cdot$ M. Moebs · C. Möller · M. Rieger · M. Roos Robert Koch-Institut, Berlin

\title{
Molekulare Virologie am Beispiel des Hepatitis-B-Virus
}

\section{Arbeiten der Nachwuchsgruppe "Hepatitis B und C: virale Genfunktionen“ des Robert Koch-Institutes}

schen dem sog. gesunden Trägerstatus (gekennzeichnet durch das Fehlen klinischer Symptomatik) und der chronischen Hepatitis zu unterscheiden ist. Weltweit ist HBV die Hauptursache für die Entstehung des hepatozellulären Karzinoms (HCC) an dem pro Jahr ca. 0,8 Mio. Menschen versterben. Nahezu alle der HBV-assoziierten HCCs sind durch die Integration von HBV-DNA in das Wirtsgenom charakterisiert.

Das Virus selbst weist eine Lipoproteinhülle auf, in die die drei viralen Oberflächenproteine LHBs (Large Hepatitis B Virus Surface Protein), MHBs (Middle Hepatitis B Virus Surface Protein) und SHBs (Small Hepatitis B Virus Surface Protein) eingelagert sind. Diese Hülle umgibt das aus dem $\mathrm{HbcAg}$ (Hepatitis-B-Virus-Core-Antigen) aufgebaute Nukleokapsid. Im Inneren des Nukleokapsids befindet sich die virale Polymerase, einige Kopien des viralen $\mathrm{HBx}$ Aktivatorproteins und das partiell doppelsträngige virale DNA-Genom. Das $\mathrm{HBV}-\mathrm{Genom}$ trägt mindestens vier verschiedene offene Leserahmen. Es kodiert für die virale Polymerase und das CoreProtein (HBcAg) bzw. seine sekretorische Variante $\mathrm{HBeAg}$, das im Unterschied zum $\mathrm{HBcAg}$ eine sekretionsvermittelnde Signalsequenz aufweist. Darüber hinaus enthält das HBV-Genom eine Sequenz für das virale Aktivatorprotein $\mathrm{HBx}$ sowie eine weitere, die für die virale Oberflächenprotein preS/S kodiert. Die zuletzt genannte Sequenz ist durch drei in frame stehende ATG-Codons (Startpunkte der Translation) in die Bereiche preS1, preS2 und $S$ untergliedert. Wird das ers- te ATG-Codon genutzt, entsteht das die PreS1-, PreS2- sowie S-Region umfassende LHBs-Protein. Ausgehend von dem zweiten ATG wird das die PreS2- und SRegion umfassende MHBs-Protein gebildet und ausgehend vom dritten ATG schließlich das die S-Region umfassende SHBs-Protein. Mithin ist die S-Region allen drei Oberflächenproteinen gemein. Im Bereich der S-Region liegen drei Transmembranregionen, sodass die viralen Oberflächenproteine klassische integrale Membranproteine darstellen. Das SHBs bildet den Hauptbestandteil der Virushülle. Darüber hinaus werden von Leberzellen (Hepatozyten), die mit HBV infiziert sind in großen Mengen subvirale Partikel, die fast ausschließlich aus SHBs und geringen Mengen LHBs bestehen, gebildet. Entsprechend ihrer Größe werden diese Aggregate, in denen sich keine virale Nukleinsäure oder andere virale Proteine befinden, auch als 22-nm-Partikel bezeichnet.

In nahezu allen HBV-assoziierten hepatozellulären Karzinomen (HCCs) wird in die Chromosomen der Tumorzellen integrierte HBV-DNA gefunden. Allerdings kann es im Zuge der Integration der DNA zu Deletionen und Umordnungen der viralen DNA kommen. Die Integration in die zelluläre DNA erfolgt unspezifisch an einem beliebigen Ort. Die integrierte virale DNA kann für zwei sog. transkriptionelle

C) Springer-Verlag 2003

Dr. Eberhard Hildt

Robert Koch-Institut, Nachwuchsgruppe I,

Nordufer 20,13353 Berlin

E-Mail:hildt@rki.de 
Aktivatoren kodieren, für das HBx-Protein sowie für die Familie der PreS2-Aktivatoren. Bei ca. 30\% der aus HCCs isolierten integrierten Genome wurden Deletionen im S-Gen gefunden, die zur Entstehung von einem verkürzten (truncated) MHBsProtein führen (z. B. MHBst76, die Zahl gibt die Verkürzung an). Im Unterschied zu dem Strukturprotein MHBs wird das verkürzte MHBs nicht sekretiert und nicht glykosyliert. Es weist eine neuartige Funktion auf, nämlich die Funktion eines sehr pleiotropen transkriptionellen Aktivators. Das heißt, es steuert indirekt die Aktivierung einer Vielzahl verschiedener Promotoren durch Interferenz mit intrazellulären Signaltransduktionswegen (im Folgenden auch Signalwege genannt). Ähnlich wie HBX ist MHBst in der Lage, eine Vielzahl verschiedener Transkriptionsfaktoren, insbesondere die Transkriptionsfaktoren AP-1 und NF- $\kappa \mathrm{B}$, zu aktivieren. Ursache für den Funktionsunterschied zwischen dem Strukturprotein MHBs und dem Aktivatorprotein MHBst ist eine topologische Umlagerung der PreS2-Region. Im Falle des Strukturproteins MHBs weist die PreS2-Region in das Lumen des endoplasmatischen Retikulums (ER) und kann mithin N-glykosyliert werden. Im Falle des MHBst-Aktivatorpoteins ist die PreS2-Region hingegen dem Zytoplasma zugewandt. Dies ermöglicht die Interaktion mit Bindungspartnern, die sich im Zytosol befinden (s. unten) und somit die Induktion von Signaltransduktionskaskaden. Arbeiten zur Topologie des LHBsProteins zeigten, dass bei einem Teil der LHBs-Proteine die PreS2-Region ebenfalls zytoplasmatisch orientiert ist. In Übereinstimmung damit konnte beobachtet werden, dass LHBs in der Tat wie MHBst ein transkriptioneller Aktivator ist. In beiden Fällen ist die zytoplasmatische Orientierung der PreS2-Region essenziell, die als die minimale transaktivierende Einheit identifiziert werden konnte. Daher werden LHBs und MHBst zur Familie der PreS2Aktivatoren zusammengefasst. MHBst kann als paradigmatisch für diese Aktivatorproteinklasse angesehen werden.

Im vorliegenden Beitrag werden nun folgende ausgewählte Projekte der Nachwuchsgruppe vorgestellt:

1. Projekt zur Charakterisierung von Signaltransduktionswegen, die durch den PreS2-Aktivator aktiviert werden. Ziel ist es, eine mögliche Funktion dieser Aktivatoren bei der HBV- assoziierten Lebertumorentstehung $\mathrm{zu}$ analysieren.

2. Im Rahmen eines weiteren Projektes wird die Relevanz der viralen Aktivatorproteine und der von ihnen aktivierten Signalwege für den viralen Lebenszyklus untersucht.

3. Im 3. Abschnitt des Beitrages werden Projekte beschrieben, die das Potenzial eines neuartigen, im Oberflächenantigen des HBV identifizierten, zellpermeablen Peptides für den Transfer von Peptiden, Proteinen und Nukleinsäuren in Zellen und Gewebe untersucht.

\section{Untersuchung HBV-abhängig aktivierter Signalkaskaden}

\section{Charakterisierung der PreS2- abhängig aktivierten Signalkaskaden}

Massenspektrometrische Untersuchungen gereinigter MHBst-Proteine gaben erste Hinweise darauf, dass es sich bei ihnen um Phosphoproteine handelt. Im Zuge weiterer Experimente konnte mittels ortsgerichteter Mutagenese die genaue Phosphorylierungsstelle im MHBstProtein identifiziert werden. Die Phosphorylierung der PreS2-Aktivatoren erfolgt an Position 28. In-vitro- und Invivo-Experimente zeigten, dass MHBst durch klassische Isoformen der ProteinKinase C (PKC) phosphoryliert wird. Selektive Hemmung oder Depletion dieser cPKC-Isoformen führen zum Verlust der PreS2-abhängigen Phosphorylierung. Interessanterweise wird MHBst nicht nur cPKC-abhängig phosphoryliert, vielmehr konnte in MHBst produzierenden Zellen auch eine permanente Aktivierung der cPKC selbst beobachtet werden. Die Hemmung der PKC führt hingegen zum Verlust der Aktivatorfunktion von MHBst, was unterstreicht, dass die Aktivierung der PKC ein essenzieller Schritt für die MHBst-abhängig induzierten Signalkaskaden ist. Mutanten, in denen die Phosphorylierungsstelle des MHBst-Proteins zerstört wurde, weisen keine Aktivatorfunktion mehr auf und interagieren nicht oder nur schwach mit der PKC. Aus diesen Beobachtungen leiten wir das folgende Modell ab (Abb. 1): MHBst interagiert über die PreS2-Region mit der Protein-Kinase C. Diese Interaktion ist der entscheidende Schritt für den Aktivierungsprozess. Die Aktivierung der PKC bewirkt eine Phosphorylierung der

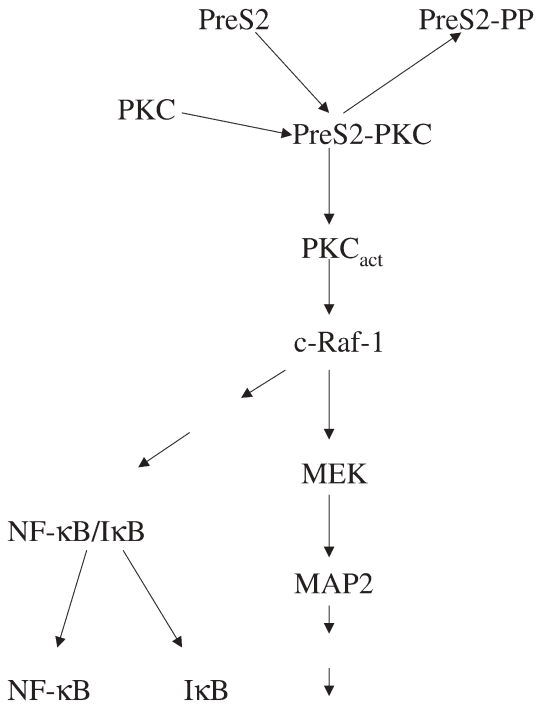

AP-1

Abb. $1 \Delta$ Schematische Darstellung der durch die PreS2-Aktivatoren LHBs (Large Hepatitis B Surface Protein) und MHBst (Middle Hepatitis B Surface Protein) aktivierten Signalkaskade. PreS2 PreS2-Region der HBV-Oberflächenproteine; PKC Protein-Kinase C; act aktiviert; c.Raf-1 zelluläre Serin/Threonin-Kinase; MEK mitogen und extrazellulär regulierte Kinase; MAP mitogen aktivierte Kinase; NfkappaB, AP-1 zelluläre Transkriptionsfaktoren; IkappaB zelluläres inhibitorisches Protein

PreS2-Region des MHBst-Proteins. Des Weiteren erfolgt nachgeschaltet eine Aktivierung der c-Raf-1/Erk2-Signalkaskade. Dies zeigt, dass die PreS2-Aktivatoren LHBs und MHBst in der Lage sind in vitro einen klassischen Tumorpromotorpathway zu stimulieren.

\section{Entwicklung von Lebertumoren in transgenen MHBst76-Mäusen}

Mäuse, in die das Gen für das LHBs-Protein des HBV stabil übertragen wurde (transgene Mäuse) und die dieses Gen spezifisch in der Leber exprimieren, entwickeln Lebertumore. In diesen Mäusen kommt es in der Leber zu einer intrazellulären Akkumulation des LHBs-Proteins, die zur Ausprägung eines Phänotyps führt, der analog einer Speicherkrankheit ist. Er ist durch das Auftreten von sog. Milchglaszellen charakterisiert. Im Zuge der intrazellulären Akkumulation kommt es zu einer permanenten Entzündung. Das Zusammenspiel dieser Prozesse scheint ursächlich für die Tumorentstehung in diesen transgenen Tieren zu sein. Vor dem Hintergrund der Beobachtung, 
dass LHBs ein transkriptioneller Aktivator ist, stellte sich jedoch die Frage, ob und inwieweit die in vitro beschriebene permanente PKC-vermittelte Aktivierung des c-Raf-1/Erk2-Signalweges zur Entstehung von Tumoren beiträgt.

Um diese Frage zu untersuchen haben wir transgene Mäuse erzeugt, die den PreS2-Aktivator MHBst76 (s. oben) leberspezifisch produzieren (exprimieren). Beim MHBst76 handelt es sich wie beim LHBs um einen PreS2-Aktivator, der als paradigmatisch für diese Klasse von Aktivatoren angesehen werden kann. Im Unterschied zu LHBs wird MHBst76 jedoch nur in sehr geringen Mengen exprimiert, sodass eine Charakterisierung von Signalwegen in Abwesenheit von unspezifischen Effekten, wie z. B. Zellstress, der durch die Expression hoher Proteinmengen bedingt sein könnte, möglich ist.

Das in die Tiere übertragene Transgen besteht aus dem humanen AlbuminPromotor, gefolgt von dem $\beta$-Globin-Intron sowie der Sequenz, die für hexahis-MHBst76 kodiert, und einer poly ASequenz des SV40-Virus. Mittels Immunfluoreszenzmikroskopie, WesternBlot-Analyse und ESI-MS (Massenspektrometrie) des gereinigten Proteins konnte in den transgenen Tieren die leberspezifische Expression des Transgens eindeutig nachgewiesen werden. Die Bestimmung verschiedener Stressparameter (wie z. B. die JNK2-Aktivität und die Expressionsmuster einzelner sog. HeatShock-Proteine) zeigte, dass es in den MHBst76 produzierenden Mäusen im Unterschied zu den LHBs-Mäusen nicht $\mathrm{zu}$ einer Induktion von Zellstress bzw. zur unspezifischen Aktivierung von Signalwegen kommt.

Mithin sind diese Mäuse ein geeignetes Werkzeug zur Charakterisierung der Signalwege, die durch PreS2-Aktivatoren spezifisch aktiviert werden. Immunokomplexassays zeigten, dass es in der Leber dieser Mäuse zu einer permanenten und deutlichen Aktivierung des cRaf-1/Erk2-Signalweges kommt. In Übereinstimmung mit diesen Befunden konnte eine deutlich erhöhte Proliferationsrate der Hepatozyten beobachtet werden. Diese führte jedoch nicht zu einer signifikanten Vergrößerung der Leber, da sie durch eine erhöhte Apoptoserate (programmierter Zelltod) kompensiert wird.

Histologische Untersuchungen des Lebergewebes zeigten, dass bei transgenen MHBst-Mäusen, die älter als 8 Mo- nate waren, Lebertumore mit hoher Inzidenz auftraten. Diese Tumore exprimieren auch das MHBst76-Protein, d.h., die PreS2-Aktivatorfunktion kann zur Tumorentstehung beitragen. Nach dem klassischen Modell der Karzinogenese (Initiation/Promotion) übt PreS2 eine Tumorpromotorfunktion aus. Übertragen auf das normale HBV-Infektionsereignis bedeutet dies, dass es im Verlaufe der Infektion, z. B. bedingt durch radikalgenerierende Abwehrmechanismen, zunächst zu Mutationen in der zellulären DNA kommen kann. Mutationen in der zellulären DNA der infizierten Zellen könnten aber auch auf der Inaktivierung von Reparaturmechanismen durch virale Proteine beruhen: So sequestriert das virale Oberflächenprotein das zelluläre p53-Protein LHBs an der Membran des endoplasmatischen Retikulums (ER). Durch die Fixierung an die ERMembran gelangt $\mathrm{p} 53$ nicht mehr in den Zellkern und kann damit seine Kontrollfunktion über die Integrität der DNA nicht mehr ausüben. Daraus resultiert im Verlaufe der Zeit eine Akkumulation kritischer Mutationen (Initiation der Karzinogenese). Zellen, die den PreS2Aktivator des HBV produzieren, können dann klonal positiv selektioniert werden (Promotion der Karzinogenese). Das Zusammenspiel dieser beiden Schlüsselschritte kann ein Mechanismus der HBV-abhängigen Karzinogenese sein.

\section{Bedeutung der Aktivator- funktion für den Prozess der HBV-Replikation}

Ausgehend von der Beobachtung, dass im Falle des HBV die Funktion als Transkriptionsaktivator in Form des LHBs und des HBx-Proteins weitgehend redundant angelegt ist, stellt sich die Frage nach der Bedeutung dieser Funktion für den viralen Lebenszyklus.

Als Parameter für die Virusreplikation wurden intra- wie extrazellulär die Menge der viralen Proteine HbeAg und HBsAg mittels ELISA, die Menge der viralen Proteine HBcAg sowie LHBs mittels Western-Blot-Analyse sowie extrazellulär die Menge HBV-spezifischer DNA mittels TaqMan-PCR (Polymerasekettenreaktion) bestimmt. Ausgehend von stabil oder transient transfizierten Zellen, zeigte sich, dass ein selektives Ausschalten der HBx-abhängigen Aktivatorfunktion in den transfizierten Zel- len (durch Hemmung des zellulären RasProteins, das essenziell für die HBx-Aktivatorfunktion ist) wie auch ein selektives Ausschalten der LHBs-abhängigen Aktivatorfunktion (Hemmung der klassischen PKC-Isoformen) keinen signifikanten Einfluss auf die Virusreplikation hat. HBx wie auch LHBs bedingen beide (im Anschluss an voneinander unterschiedlichen initialen Schritten) eine Aktivierung der c-Raf-1/MEK/Erk2-Signalkaskade. Die Hemmung des zellulären cRaf-1-Proteins durch die Expression einer sog. Trans-dominant-negativen $\mathrm{Mu}$ tante, wie auch die Hemmung der in der Kaskade nachfolgenden Kinase MEK mittels selektiver chemischer Inhibitoren, führte zu einer vollkommenen Unterbindung der viralen Replikation. Es zeigte sich, dass es durch diese Inhibitoren nicht zu einem Block in der Sekretion der viralen Partikel oder zu einer intrazellulären Akkumulation einzelner viraler Bestandteile kommt. Vielmehr erfolgt eine drastische Reduktion der Neusynthese aller viralen Bestandteile, d.h. der Proteine wie auch - im Unterschied zu vielen anderen antiviralen Strategien der viralen RNA/DNA.

Ähnliche Ergebnisse wurden im Rahmen von Mutageneseexperimenten erzielt: Nach Transfektion eines HBx-defizienten HBV-Genoms bzw. eines Genoms mit inaktivem LHBs-Aktivator produzierten die Zellen nahezu die gleiche Zahl an Viren wie nach Transfektion mit einem Wildtyp-Genom. Zellen, die doppelt mutierte Genome enthalten, die weder $\mathrm{HBx}$ noch ein funktionelles LHBs-Aktivatorprotein bilden, setzen hingegen keine HBV-Viren mehr frei.

Diese Ergebnisse zeigen, dass die durch transkriptionelle Aktivatorproteine vermittelte Aktivierung der c-Raf1/MEK/Erk2-Signalkaskade essenziell für den Ablauf der viralen Replikation ist, um eine hinreichende Neusynthese der viralen Bestandteile sicherzustellen, indem eine Aktivierung der viralen Genexpression erfolgt.

\section{Identifizierung eines zell- permeablen Peptides in der PreS2-Region von HBsAg}

Die PreS2-Region des HBV-Oberflächenantigens ist ein zellpermeables Protein: Die Eigenschaft der Zellpermeabilität dieser Region wird durch eine kurze ampiphile $\alpha$-Helix vermittelt (Abb. 2). 
Dieses 12 Aminosäuren umfassende Peptid, nachfolgend TLM (Translocation Motif) genannt, vermittelt den rezeptor- und energieunabhängigen Transfer von Peptiden, Proteinen oder Nukleinsäuren in Zellen, sofern es kovalent oder nicht-kovalent mit ihnen verbunden ist. Auffallend ist, dass zwischen den verschiedenen Hepadnaviridae zwar nicht die Sequenz, jedoch das Verteilungsmuster hydrophiler und hydrophober Aminosäuren innerhalb einer $\alpha$-Helix sehr hoch konserviert ist, was auf eine mögliche Bedeutung des TLMs für den viralen Lebenszyklus hindeutet.

\section{Einsatz des TLM-Peptides zum Protein- und Peptidtransfer}

Das TLM besitzt keine Gewebespezifität. Es könnte damit als biotechnologisches Werkzeug verwendet werden, um eine hocheffiziente Übertragung von gewünschten Peptiden und Proteinen in Zellen und Gewebe zu erreichen. Durch Protein- bzw. Peptidtransfer bedingte Effekte sind direkt an die Halbwertszeit des transferierten Agens gekoppelt und somit leichter regulierbar als durch den herkömmlichen Gentransfer induzierte Effekte. Basierend auf zellpermeablen Peptiden, die selektiv Protein/ProteinInteraktionen kompetitieren, konnten z.B. hochspezifische Modulatoren intrazellulärer Signalwege etabliert werden. So ist beispielsweise die TNF-abhängige

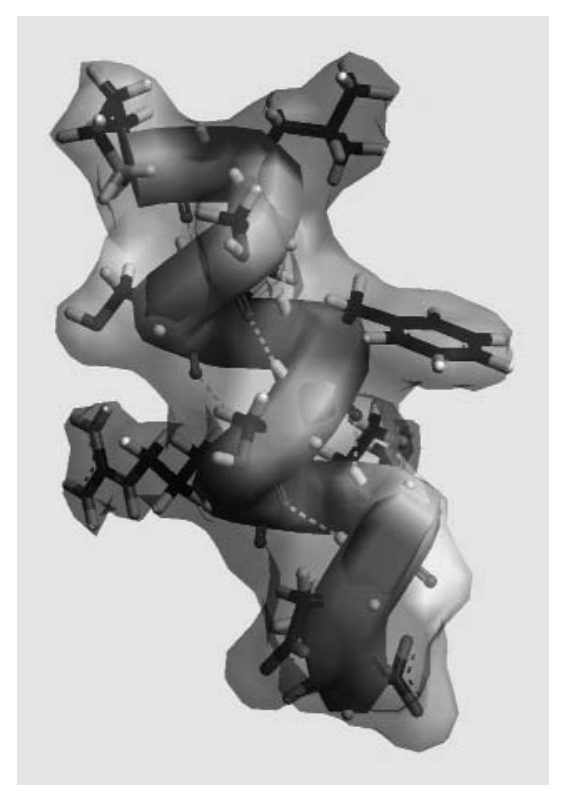

Abb. $2 \Delta$ Struktur des zellpermeablen TLMPeptides

\section{TLM-HBCAg-Dimer}

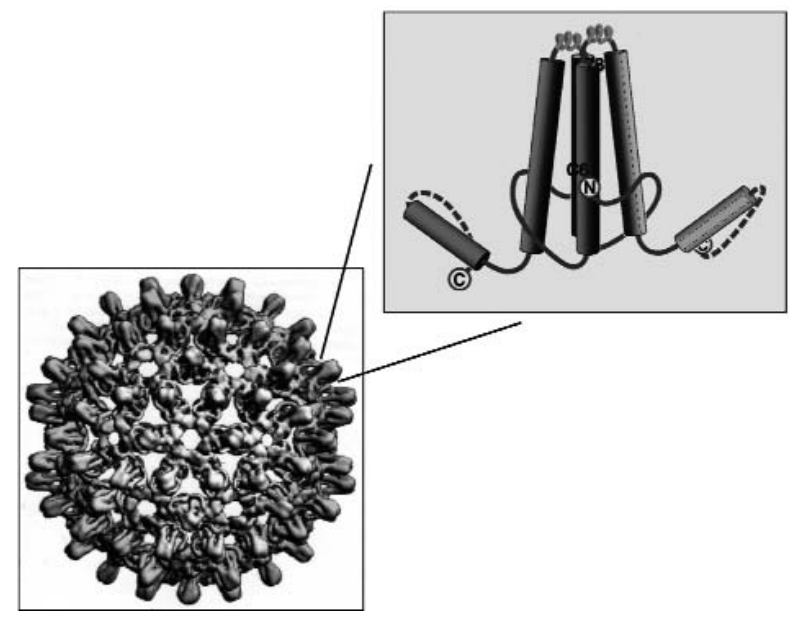

Aktivierung von c-Raf-1 mittels zellpermeabler Peptide, welche die TNF-RI/ Grb2-Interaktion kompetitieren, selektiv hemmbar.

Durch zellpermeable Peptide lässt sich auch die Interaktion des HBVOberflächenantigens mit dem Nukleokapsid, die essenziell für die Morphogenese des HBV-Virus ist, kompetitieren. Mittels solcher Peptide ist eine exakte Charakterisierung der in vivo interagierenden Domänen möglich.

Zellpermeable Proteine sind auch bereits zur Modulation der Aktivität des p53-Tumorsuppressors zum Einsatz gekommen. Ein wesentlicher Parameter für die Funktion von p53 ist die Fähigkeit zur Tetramerisierung. Die p53-Tetramerisierung wird durch die sog. Tetramerisierungsdomäne vermittelt, die sich aus einem $\beta$-Faltblatt und einem $\alpha$-helicalen Sekundärstrukturelement aufbaut. Mittels zellpermeabler Fusionspeptide, die diese Sekundärstrukturelemente ganz oder teilweise beinhalten, kann nun die Aktivität von p53-Wildtyp bzw. mutiertem p53 moduliert werden.

\section{Verstärkung des Bystander-Effekts von Suizidgentherapeutika durch Einsatz des TLM-Peptides}

Im Unterschied $\mathrm{zu}$ anderen bekannten zellpermeablen Peptiden ist das TLM, wie nachfolgend beschrieben, auch in der Lage, den Transport größerer Proteine über Zellmembranen zu vermitteln. Es ermöglicht nicht nur den Transport von Proteinen in die Zellen hinein, sondern, da es sich um einen freien Diffusionsprozess handelt, auch aus ihnen hin- aus. Damit könnte der Einsatz des TLM als Transfersystem eine drastische Verstärkung des sog. Bystander-Effekts von Suizidgentherapeutika erlauben. Das Konzept der Suizidgentherapie zur Behandlung von Tumorknoten solider Organe - wie z. B. der Leber - basiert auf der Übertragung eines sog. Suizidgenes in die Tumorzellen. Als Resultat dieser Übertragung werden systemisch applizierte, nichttoxische Pharmaka (sog.prodrugs) in den Tumorzellen in toxische Metaboliten umgewandelt, und es kommt zur Abtötung der Tumorzellen. Mit dieser Methode lassen sich lokal, d.h.im Bereich des erfolgten Gentransfers, sehr hohe Konzentrationen des toxischen Metaboliten erzielen, während die systemische Toxizität, die bei konventionellen Chemotherapeutika auftritt, vermieden werden kann. Als Suizidgen wird in gegenwärtigen Gentherapiestudien häufig das Cytosin-Desaminase- (CDase-) Gen verwendet. Dieses Gen kodiert für ein Enzym, das die nicht toxische Substanz 5-Fluorcytosin (5-FC) in den toxischen Metaboliten 5-Fluoruracil (5-FU) umwandeln kann, das in der Chemotherapie zur Behandlung diverser Karzinomitäten (Rektum, Kolon, Mamma, Magen, Pankreas) eingesetzt wird. In den gegenwärtig durchgeführten Gentherapiestudien ist allerdings die Effizienz mit der Suizidgene in die Tumorzellen übertragen werden können - aufgrund methodischer Probleme - noch sehr gering, d.h., die Tumorzellen lassen sich nicht im erforderlichen Umfang abtöten. Durch Transfer eines Genkonstruktes, das für ein zellpermeables TLM-CDaseFusionsprotein kodiert, in die Tumorzel- 


\section{Forschung aktuell}

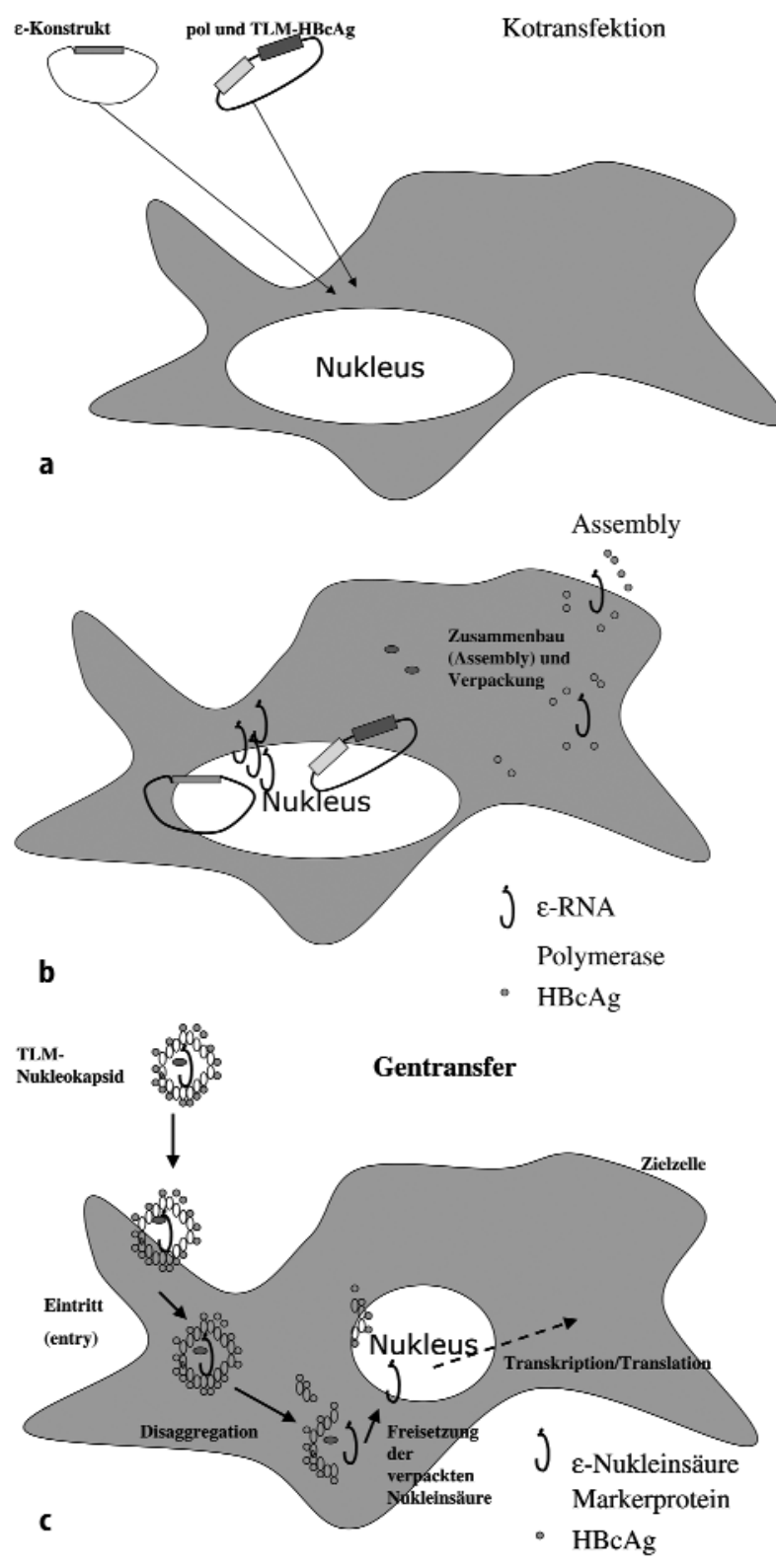

Abb. 4a-c $\boldsymbol{\Delta}$ Schematische Darstellung der Herstellung zellpermeabler Nukleokapside. a Transfektion vonZellen mit den für zellpermeable Nukleokapside kodierenden Expressionskonstrukten.b Ausgehend von den eingebrachten Expressionskonstrukten baut die Zelle zellpermeable Nukleokapside auf, die aus dem Kulturüberstand isoliert werden können und dann c zur Transfektion der jeweiligen Zielzelle/-gewebe verwendet werden können. Als Markergen dient die Expression des verpackten eGFP-Gens. $\varepsilon$ DNAVerpackungssignal; pol Polymerase; TLM Translocation Motif, d. h. zellpermeables Peptid des HBV-Oberflächenantigens; HBcAg Hepatitis-B-Virus-Core-Antigen; eGFP Grün-fluoreszierendes Protein

len, lässt sich diese Effizienz jedoch drastisch erhöhen. Der Grund dafür ist, dass das TLM-CDase-Fusionsprotein im Unterschied zur bisher verwendeten konventionellen CDase aus der transfizierten Tumorzelle (producer-Zelle) in das umliegende Gewebe diffundieren (spreading) und so auch dort 5-FC zu 5FU metabolisieren kann. Folglich erreicht der toxische Metabolit eine größere Zahl von Tumorzellen.

\section{Einsatz des TLM-Peptides zum Gentransfer}

Das TLM-Peptid kann auch zum Gentransfer verwendet werden. Für einen effizienten In-vitro- und In-vivo-Gentransfer auf der Basis des TLMs werden gegenwärtig zwei verschiedene Strategien entwickelt.

Ein sehr einfacher Ansatz basiert auf einem Fusionsprotein, das aus 4 Mo- dulen aufgebaut ist: Es besteht aus einem hexa-his tag zur leichten Isolierbarkeit des Proteins, dem TLM-Peptid selbst zur Vermittlung der Zellpermeabilität, der DNA-Bindungsdomäne aus dem Hefetranskriptionsfaktor $\mathrm{Gal}_{4}$ sowie aus einem NLS (Nuclear Localication Signal), um den Kerntransport der an das Fusionsprotein gebundenen und zu übertragenden Nukleinsäure in der Zelle zu ermöglichen. Diese 6H-TLM-Gal4-NLSFusionsproteine können nun über die DNA-Bindungsdomäne mit Nukleinsäuren beladen werden. In den Modellexperimenten wurde eine DNA verwendet, die für ein leicht nachweisbares Markerprotein (eGFP, enhanced Green Fluorescent Protein) kodiert, um den Gentransfer direkt anhand der Grünfluoreszenz des gebildeten Proteins beobachten zu können. Es zeigte sich, dass damit ein effizienter Transfer von Nukleinsäuren in kultivierte Zellen möglich ist.

\section{Einsatz zellpermeabler Nukleokap- side zum Gen- bzw. Epitoptransfer}

Ein alternativer Ansatz basiert auf zellpermeablen Nukleokapsiden (virus like particles). Die Kapside des HBV bauen sich aus einzelnen HBcAg-Monomeren auf. Das HBcAg weist sog. spike tips auf, also Strukturen, die aus der Oberfläche des fertigen Kapsidpartikels herausragen. In diese spike tips können (ohne dass die Partikelbildung beeinträchtigt wird) Fremdsequenzen, in diesem Fall die Sequenz des TLMs-Peptides, eingefügt werden. Es entstehen damit Kapside, die auf der Oberfläche das die Zellpermeabilität vermittelnde TLM tragen (Abb. 3). In Kapside des HBV können nun Nukleinsäuren verpackt werden. Voraussetzung dafür ist einerseits das Vorliegen einer Zelllinie, die die HBVPolymerase produziert (Verpackungszelllinie) und andererseits die Existenz eines kurzen Verpackungssignals $(\varepsilon)$ auf der Nukleinsäure. Sind diese Faktoren vorhanden, so können aus den TLM$\mathrm{HBcAg-Monomeren} \mathrm{zellpermeable} \mathrm{Nu-}$ kleokapside aufgebaut werden, in die spezifisch die gewünschte Nukleinsäure verpackt wird (Abb. 4a-c). Als Markergen dient wiederum eGFP, um den Gentransfer mittels dieser zellpermeablen Nukleokapside anhand der Grünfluoreszenz untersuchen zu können.

Alternativ dazu können solche Kapside in E. coli produziert und nach der 


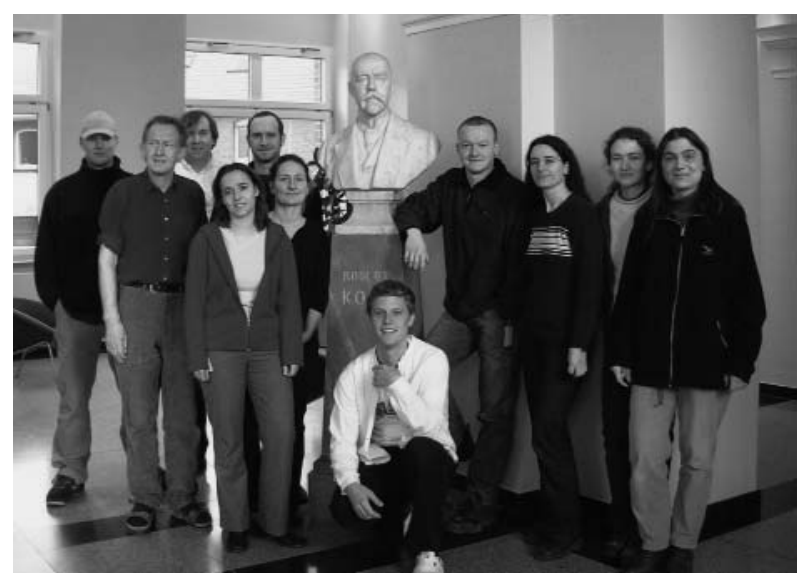

Abb. $5<$

Mitarbeiter der Arbeitsgruppe

Reinigung in ihre HBcAg-Monomere dissoziiert werden. Erfolgt die Reassoziation in Gegenwart einer Nukleinsäure, so wird diese in die sich wieder zusammenlagernden Kapsidpartikel verpackt. Dieses Verfahren kombiniert die Vorteile des viralen Gentransfers (Effizienz und Schutz der zu transferierenden Nukleinsäure vor Degradation) mit denen des nicht-viralen Transfers (hohe biologische Sicherheit, da außer dem 20 Nukleotide umfassenden Verpackungssignal keine viralen Sequenzen transportiert werden). Da in HBV-Nukleokapside nur maximal 3,2 kB große Nukleinsäuren verpackt werden können, soll in der Arbeitsgruppe (Abb. 5) nun, nachdem der "Proof of Principle“ erbracht ist, versucht werden, auch Kapside anderer Viren, die die Verpackung größerer Nukleinsäuren ermöglichen, als Transfektionagens zu verwenden.

Zellpermeable Kapside sind darüber hinaus nicht nur zum Gentransfer, sondern auch zum Epitoptransfer geeignet. Das Epitop wird hierbei in das $\mathrm{HBcAg-Monomer} \mathrm{eingefügt,} \mathrm{sodass} \mathrm{das}$ sich daraus aufbauende Kapsidpartikel als Epitopträger fungiert. Solche epitoptragenden Partikel stellen ein gutes Werkzeug zur Induktion einer T-ZellImmunantwort, aber auch einer B-ZellAntwort dar.

\section{Ausblick}

Aufbauend auf den für das Hepatitis-BVirus gefundenen Ergebnissen, werden nun ähnliche Experimente zur Charakterisierung der Aktivatorproteine des Hepatitis-C-Virus durchgeführt. Ziel ist in beiden Fällen, durch selektive Hemmung von Signalwegen die Manifestati- on einer Infektion zu verhindern bzw. die Entstehung eines virusassoziierten HCCs zu beeinflussen. Im Rahmen weiterer Arbeiten zur Charakterisierung des TLMs soll zum einen die Bedeutung dieses Motivs für den viralen Lebenszyklus eingehender charakterisiert werden. Zum anderen sollen auf der Basis dieses Moleküls neue Ansätze zur hochselektiven Modulation intrazellulärer Signalwege sowie des Immunsystems entwickelt werden.

\section{Weiterführende Literatur}

1. Hildt E, Urban S, Hofschneider PH (1995) Characterization of essential domains for the functionality of the MHBst activator and identification of a minimal MHBst activator. Oncogene 11:2055-2066

2. Hildt E, Saher G, Bruss V, Hofschneider PH (1996) The hepatitis $B$ virus large surface protein (LHBs) is a transcriptional activator.Virology 225:235-239

3. Hildt E, Urban S, Eckerskorn C, Hofschneider PH (1996) Isolation of highly purified, functional carboxyterminally truncated hepatitis B virus middle surface activators from eucaryotic expression systems. Hepatology 24:502-507

4. UrbanS, Hildt E (1994) Use of Ni-NTA-resin for isolation o cellular proteins binding to HBV transactivator proteins $\mathrm{Hbx}$ and MHBst. Quiagen News 3

5. Hildt E, Hofschneider PH, Urban S (1996) The role of Hepatitis B Virus in the development of hepatocellular carcinoma. Sem Virol 333-347

6. Weiss L, Hildt E, Hofschneider PH (1996). Antihepatitis B virus activity of $\mathrm{N}$-acetyl-L-cysteine (NAC): new aspects of a well-established drug. Antiviral Res 32:43-53
7. Urban S, Hildt E, Eckerskorn C et al. (1998). Onestep purification of hepatitis $B$ virus $X$ protein from a Baculovirus expression system and its characterization by mass spectrometry. Hepatology 26:1045-1053

8. Hildt E, Hofschneider PH (1998) The PreS2 activators of the hepatitis $B$ virus: activators of tumour promoter pathways. Recent Res Cancer Res 154:313-329

9. Rothmann K, Schnoelzer M, Radziwill $G$ et al. (1998) Host cell-virus cross talk: phosphorylation of a hepatitis $B$ virus envelope protein mediates intracellular signaling. JVirol 72:10138-10147

10. Hildt $\mathrm{E}$, Oess $\mathrm{S}$ (1999). Identification of Grb2 as a novel binding partner of tumor necrosis factor (TNF) receptor I.J Exp Med 189:1707-1714

11. Saher G, Hildt E (1999) Activation of c-Raf-1 kinase signal transduction pathway in alpha (7) Integrin-deficient mice.J Biol Chem 274:27651-27657

12. Hildt E, Oess S, Wollersheim (1999) Cellpermeable Gal4-DNA-binding domain as an efficient tool in gene transfer (abstr.). J Gene Med [Suppl] 1:31

13. Oess S, Loeffelbein F, Hildt E (1999) Modulation of $\mathrm{p} 53$ activity by cell permeable peptides (abstr.).J Gene Med [Suppl] 1:31

14. Stöckl I, Oess S, Hofschneider PH, Hildt E (1999) Recombinant cellpermeable hepatitis $B$ virusderived nucleocapsid particles as a novel tool for gene transfer (abstr.). J Gene Med [Suppl] 1:35

15. Oess S, Hildt E (2000) Identification of a novel cell permeable peptide derived from the Hepatitis $B$ virus surface antigen. Gene Therapy 7:750-758

16. Hübinger G, Müller E, Scheffrahn I et al. (2001) CD30 mediated cell cycle arrest is associated with induced expression of p21 Oncogene 20:590-598

17. Chang SF, Netter HJ, Hildt E et al. (2001) Duck hepatitis $B$ virus expresses a regulatory $\mathrm{HBx}$ like protein from a hidden open reading frame. JVirol 75:161-170

18. Hildt E, Munz B, Saher G et al. (2002) The PreS2 activator MHBst of the Hepatitis b virus activates c-raf-1/ERK2- signaling in transgenic mice. EMBO J 21:525-535

19. Munz B, Hildt E, Springer M, Blau H (2002) RIP2, a checkpoint in myogenic differentiation, Mol Cell Biol 22:5879-5886

20. Schuster R, Hildt E, Chang $S$ et al. (2002) Conserved transactivating and pro-apoptotic functions of hepadnaviral $X$ protein in ortho- and avihepadnaviruses. Oncogene 21:6606-6613

21. StoeckI L, Berting A, Malkowski B et al. (2003) Integrity of the c-Raf-1/MEK signal transduction cascade is essential for HBV-replication, Oncogene, 22:2604-2611 